\title{
On the extraordinary low quench sensitivity of an AlZnMg alloy
}

\author{
Christian Rowolt ${ }^{1}$, Benjamin Milkereit ${ }^{1,2,7, *}$ (D) Armin Springer $^{3}$, Mami Mihara-Narita ${ }^{4}$, \\ Hideo Yoshida ${ }^{5}$, Kenya Yamashita ${ }^{6}$, Kevin Oldenburg ${ }^{7}$, and Olaf Kessler ${ }^{1,2,7}$ \\ ${ }^{1}$ Chair of Materials Science, Faculty of Mechanical Engineering and Marine Technology, University of Rostock, Rostock, Germany \\ ${ }^{2}$ Competence Centre ${ }^{\circ} \mathrm{CALOR}$, Department Life, Light \& Matter, University of Rostock, Rostock, Germany \\ ${ }^{3}$ Electron Microscopic Centre, University Medical Centre Rostock, Rostock, Germany \\ ${ }^{4}$ Department of Physical Science and Engineering, Nagoya Institute of Technology, Nagoya, Japan \\ ${ }^{5}$ ESD Laboratory, Nagoya, Japan \\ ${ }^{6}$ Research Department I, Research and Development Division, Material Fundamental Research Section, UACJ Corporation Nagoya, \\ Nagoya, Japan \\ ${ }^{7}$ Centre for Interdisciplinary Electron-Microscopy (ELMI-MV), Department Life, Light and Matter, University of Rostock, Rostock, \\ Germany
}

Received: 25 August 2021

Accepted: 29 September 2021

Published online:

12 October 2021

(C) The Author(s) 2021

\begin{abstract}
The scope of this work was to investigate the quench sensitivity of a high-purity wrought aluminum alloy Al6Zn0.75 Mg (in this work called $7003_{\text {pure }}$ ). This is compared to a similar alloy with the additions of $\mathrm{Fe}, \mathrm{Si}$, and $\mathrm{Zr}$ at a sum less than 0.3 at.\% (in this work called $7003_{\mathrm{Fe}, \mathrm{Si}, \mathrm{Zr}}$ ). Differential scanning calorimetry (DSC) was used for an in situ analysis of quench induced precipitation in a wide range of cooling rates varying between 0.0003 and $3 \mathrm{~K} / \mathrm{s}$. In $7003_{\text {pure, }}$ three main precipitation reactions were observed during cooling, a medium temperature reaction with a distinct double peak between 325 and $175{ }^{\circ} \mathrm{C}$ and a very low temperature reaction starting at about $100{ }^{\circ} \mathrm{C}$. An additional high temperature reaction related to the precipitation of $\mathrm{Mg}_{2} \mathrm{Si}$ starting at $425{ }^{\circ} \mathrm{C}$ has been observed for $7003_{\mathrm{Fe}, \mathrm{Si}, \mathrm{Zr}}$. In terms of hardness after natural as well as artificial aging, alloy $7003_{\text {pure }}$ shows a very low quench sensitivity. Hardness values on the saturation level of about 120 HV1 are seen down to cooling rates of $0.003 \mathrm{~K} / \mathrm{s}$. The as-quenched hardness $(5 \mathrm{~min}$ of natural aging) shows a maximum at a cooling rate of $0.003 \mathrm{~K} / \mathrm{s}$, while slower and faster cooling results in a lower hardness. In terms of hardness after aging, $0.003 \mathrm{~K} /$ $\mathrm{s}$ could be defined as the technological critical cooling rate, which is much higher for $7003_{\mathrm{Fe}, \mathrm{Si}, \mathrm{Zr}}(0.3-1 \mathrm{~K} / \mathrm{s})$. The physical critical cooling rates for the suppression of any precipitation during cooling were found to be about $10 \mathrm{~K} / \mathrm{s}$ for both variants.
\end{abstract}

Handling Editor: Sophie Primig.

Mami Mihara-Narita, Hideo Yoshida formerly UACJ Corporation, Japan

Address correspondence to E-mail: benjamin.milkereit@uni-rostock.de 


\section{Introduction}

Alloys from the system Al-Zn-Mg (7xxx) combine high strength with low weight as well as good formability, which are important features for applications in the transportation industry, such as aerospace, automotive, or trains [1, 2]. To adjust the strength of 7xxx alloys, the heat treatment precipitation hardening consisting of solution annealing, quenching, and aging is conducted [3]. During solution annealing, the alloying elements are being dissolved and homogeneously distributed in the aluminum matrix followed by a more or less rapid quenching to room temperature. The latter typically aims to result in a fully supersaturated solid solution. In the last step, the material will be aged to promote the formation of a high number density of nanoscaled precipitates. These hinder dislocation glide and thereby significantly increase the yield strength. In this process, quenching is a critical technological step. On the one hand, quenching has to be fast enough to fully suppress precipitation during cooling to achieve high strength after aging. On the other hand, excess residual stresses and distortion due to rapid quenching must be avoided. The reduction in properties (e.g., strength, ductility, toughness, corrosion resistance) due to falling cooling rates (i.e., quenchinduced precipitation) is described by the term quench sensitivity [4-6].

In 1965, Baba applied for a patent for an Al-Zn-Mg alloy with zirconium added instead of chromium. He developed $\mathrm{Al}-\mathrm{Zn}-\mathrm{Mg}$ alloys with zirconium added for the first time named Sumitomo Alloy ZK47, ZK141. These alloys have been put into practical use as JIS A 7N01 (now AA7204). In 1967, Sumitomo Alloy ZK60 (now 7003) was developed with a reduced amount of $\mathrm{Mg}$ and improved extrudability [7-9]. It can be extruded with direct air-cooling at press-outlet to obtain medium-strength [10-13]. This alloy has been registered with AA (The Aluminum Association) as 7003 in 1975. Zirconium was added for the first time instead of chromium as a dispersoid forming element $[8,9]$. Finally, it was used for Series 200 Shinkansen structures as well as motorcycle frames and rims. Yoshida et al. investigated the relationship between the ingot homogenization conditions and mechanical properties of zirconiumadded alloys [14]. It was found that the addition of approximately 0.2 mass\% zirconium improves the strength and stress corrosion resistance. Zirconium as an alloying element leads to the formation of spherical dispersoids $\mathrm{Al}_{3} \mathrm{Zr}$ during homogenization. However, this results in a higher quench sensitivity since the crystal-lattice misfit between the aluminum matrix and dispersoids favors the precipitation of $\eta$ $\mathrm{MgZn}_{2}$ during cooling. Meanwhile, $\mathrm{Al}_{3} \mathrm{Zr}$ dispersoids are reported to act as nucleation sites for quenchinduced $\eta-\mathrm{MgZn} n_{2}$ or $\eta-\mathrm{Mg}(\mathrm{Zn}, \mathrm{Cu}, \mathrm{Al})_{2}$ formation in multiple $\operatorname{AlZnMg}(\mathrm{Cu})$ alloys at least in the case that they have an incoherent interface with the matrix $[4,6,15,16]$.

The addition of iron and silicon to 7003 results in coarse intermetallic particles enriched in $\mathrm{Al}, \mathrm{Si}$, and Fe [17], which likely form as primary particles in the melt. Those types of intermetallic particles are also known to act as nucleation sites for quench induced precipitates at high temperatures for a broad range of technical $\mathrm{Al}$ alloys [6], particularly $\beta-\mathrm{Mg}_{2} \mathrm{Si}$ nucleates on these coarse Al-Si-Fe-rich intermetallics [17].

In Ref. [8], Baba also reported on the Vickers hardness of a "pure" variation of alloy 7003 containing only the alloying elements magnesium and zinc. He observed a very low quench sensitivity, as this "pure" alloy reached about $94 \%$ of the maximum hardness for slow cooling $(0.025 \mathrm{~K} / \mathrm{s})$ from the solution annealing temperature compared to water quenched samples after artificial aging at $120^{\circ} \mathrm{C}$ [8]. Later, Yoshida et al. found that in this "pure" alloy under certain conditions, the hardness of furnacecooled samples is even higher than that of water quenched samples [18].

The scope of this work is to further investigate the quench sensitivity and the mechanism of quench induced precipitation (QIP) of this high wrought purity aluminum alloy Al6Zn $0.75 \mathrm{Mg}\left(7003_{\text {pure }}\right)$ in comparison with a variant with the additions of $\mathrm{Fe}$, $\mathrm{Si}$, and $\mathrm{Zr}$. Differential scanning calorimetry (DSC) is accompanied by hardness tests as well as extensive micro- and nano-structural investigations.

\section{Materials and methods}

The alloy $7003_{\text {pure }}$ was produced by the UACJ, Japan. Samples for this work were prepared out of an extruded rod with a diameter of $20 \mathrm{~mm}$ and a length of $200 \mathrm{~mm}$. After casting, the material was homogenized at $500{ }^{\circ} \mathrm{C}$ for $8 \mathrm{~h}$, and extrusion was done after heating to $400{ }^{\circ} \mathrm{C}$. Table 1 shows the mass and atomic 
fractions of the alloying elements in the $7003_{\text {pure }}$ samples as determined by optical emission spectroscopy (OES).

In addition to the comprehensive investigation on $7003_{\text {pure, }}$ at some points, a direct comparison with a commercially extruded profile $7003_{\mathrm{Fe}, \mathrm{Si}, \mathrm{Zr}}$ will be discussed. The main difference between both alloys is the amount of $\mathrm{Fe}, \mathrm{Si}$, and $\mathrm{Zr}$ (in sum less than 0.3 at.\%, see Tables 1 and 2).

DSC cooling experiments were performed and evaluated regarding the specific excess heat capacity according to Ref. [19]. The cooling rates were varied in a wide range from $0.0003 \mathrm{~K} / \mathrm{s}$ to $1 \mathrm{~K} / \mathrm{s}$ to comprehensively analyze the solid-solid phase transformation behavior. The following three different DSC devices were used to cover this enormous cooling rate range by in situ cooling DSC along with each specific sample size and sample mass:

- Setaram C600 (heat flow DSC): Ø $13.8 \times 60.5 \mathrm{~mm}$ $\approx 24,700 \mathrm{mg}$

- Setaram Sensys \& DSC121 (heat flow DSC): $\varnothing 6 \times 21.65 \mathrm{~mm} \approx 1700 \mathrm{mg}$

- Perkin Elmer Pyris Diamond (power compensated DSC): $\varnothing 6.4 \times 1 \mathrm{~mm} \approx 90 \mathrm{mg}$.

In the case of the faster cooling rates realized in the Perkin Elmer Pyris Diamond DSC, linear cooling was done down to $-50{ }^{\circ} \mathrm{C}$, while slower cooling experiments ended at about $20^{\circ} \mathrm{C}$.

To obtain additional information on the effect of varying cooling rates on the subsequent mechanical properties, Vickers hardness tests HV1 (ISO 6507) were carried out using a Shimadzu type HMV-2 micro hardness tester on the solution annealed and quenched samples as well as in aged conditions. "Asquenched "-condition means about $5 \mathrm{~min}$ after the end of cooling. The hardness was tested after 7, 28, 245 , and 365 days of natural aging. Additionally, artificially aging, i.e., cooling from solution treatment at distinct rates, for $5 \mathrm{~min}$ at room temperature and aging at $120^{\circ} \mathrm{C}$ for $24 \mathrm{~h}$ was compared. Samples for the hardness tests and microstructure investigations were solution annealed and quenched in a Perkin Elmer Pyris Diamond DSC (cooling rates:
$0.0003-1 \mathrm{~K} / \mathrm{s}$ ). Faster cooling was achieved with a Bähr DIL 805 A/D quenching dilatometer (cooling rates: $3-100 \mathrm{~K} / \mathrm{s}$ ). For this purpose, cylindrical samples with a diameter of $6.4 \mathrm{~mm}$ and a length of $1 \mathrm{~mm}$ were used. To analyze the changes in the microstructure related to the reactions detected in DSC, optical microscopy (OM) as well as scanning electron microscopy (SEM) and energy-dispersive $\mathrm{X}$-ray spectroscopy (EDS) were performed. The heattreated samples were cold-embedded in epoxy resin and then mechanically ground and polished with water-free lubricants. The final polishing was done with a $0.05 \mu \mathrm{m}$ polishing suspension. The polished samples were rinsed and etched as per Weck $(4 \mathrm{~g}$ potassium permanganate $\mathrm{KMnO}_{4}, 1 \mathrm{~g}$ caustic soda $\mathrm{NaOH}, 100 \mathrm{ml}$ water $\mathrm{H}_{2} \mathrm{O}$ ) [20].

The SEM samples were analyzed by a field emission SEM (MERLIN®VP Compact, Co. Zeiss, Oberkochen, Germany) equipped with an EDS detector (XFlash 6/30) and analysis software (Quantax400, Co. Bruker, Berlin, Germany). The embedded and polished samples were mounted on the SEM carrier with adhesive conductive carbon and aluminum tape (Co. PLANO, Wetzlar, Germany). SEM-secondary electron (SEM-SE) images were obtained using a high efficiency Everhart-Thornley-type HE-SE detector at $5 \mathrm{kV}$ acceleration voltage. Representative areas of the samples were analyzed and mapped to determine the elemental distribution on the basis of the EDS spectra data by the QUANTAX ESPRIT Microanalysis software (version 2.0). The acceleration voltage for the EDS analysis was set to $20 \mathrm{kV}$.

A Bruker Discover D8 X-ray diffractometer was applied to identify relevant phases after very slow cooling at $0.0003 \mathrm{~K} / \mathrm{s}$. The diffractometer was equipped with a $\mathrm{Cu} \mathrm{K \alpha}$ source of wavelength $0.15406 \mathrm{~nm}$ using $40 \mathrm{kV}$ and $40 \mathrm{~mA}$. In detail, a step size of $0.04^{\circ}$ with a measuring time per angular step of $1.4 \mathrm{~s}$ from 20 to $120^{\circ}$ was set to collect the data.

The nanostructure of the slowly cooled and naturally aged samples was investigated in an analytical, probe aberration corrected scanning transmission electron microscope (STEM) JOEL JEM-ARM200F NEOARM equipped with a cold field emission gun
Table 1 Fractions of alloying elements in $7003_{\text {pure }}$ according to optical emission spectroscopy

\begin{tabular}{lllllllllll}
\hline & $\mathrm{Si}$ & $\mathrm{Fe}$ & $\mathrm{Cu}$ & $\mathrm{Mn}$ & $\mathrm{Mg}$ & $\mathrm{Cr}$ & $\mathrm{Zn}$ & $\mathrm{Ti}$ & $\mathrm{Zr}$ & $\mathrm{Al}$ \\
\hline Mass\% & 0.01 & 0.02 & $<0.01$ & $<0.001$ & 0.77 & $<0.001$ & 6.1 & $<0.01$ & - & Bal \\
at.\% & $\mathbf{0 . 0 1}$ & $\mathbf{0 . 0 1}$ & $<\mathbf{0 . 0 1}$ & $<\mathbf{0 . 0 0 1}$ & $\mathbf{0 . 8 9}$ & $<\mathbf{0 . 0 0 1}$ & $\mathbf{2 . 6 1}$ & $<\mathbf{0 . 0 1}$ & - & Bal \\
\hline
\end{tabular}


Table 2 Fractions of alloying elements in $7003_{\mathrm{Fe}, \mathrm{Si}, \mathrm{Zr}}$ according to optical emission spectroscopy

\begin{tabular}{lllllllllll}
\hline & $\mathrm{Si}$ & $\mathrm{Fe}$ & $\mathrm{Cu}$ & $\mathrm{Mn}$ & $\mathrm{Mg}$ & $\mathrm{Cr}$ & $\mathrm{Zn}$ & $\mathrm{Ti}$ & $\mathrm{Zr}$ & $\mathrm{Al}$ \\
\hline Mass\% & 0.11 & 0.20 & 0.01 & - & 0.68 & - & 5.56 & 0.02 & 0.17 & Bal \\
at.\% & 0.11 & 0.10 & 0.004 & - & 0.78 & - & 2.37 & 0.01 & 0.05 & Bal \\
\hline
\end{tabular}

operated at $200 \mathrm{kV}$ acceleration voltage. Images were acquired by a high-angle annular dark field detector (HAADF), and the chemical composition of relevant features were analyzed by a JEOL energy-dispersive $X$-ray (EDS) detector with an area of $100 \mathrm{~mm}^{2}$.

For TEM, a thin disk of about $300 \mu \mathrm{m}$ thickness was cut from the DSC sample by a diamond precision saw. This disk was ground and polished to a thickness of about $80 \mu \mathrm{m}$. The final electrolytical thinning was done by a STRUERS Tenupol 5 operated at $30{ }^{\circ} \mathrm{C}$ using an electrolyte consisting of $65-85 \%$ ethanol $\mathrm{C}_{2} \mathrm{H}_{6} \mathrm{O}$, 10-15\% 2-butoxy-ethanol $\mathrm{C}_{6} \mathrm{H}_{14} \mathrm{O}_{2}$, and $5-15 \%$ water $\mathrm{H}_{2} \mathrm{O}$.

\section{Results and discussion}

\section{Quench-induced precipitation analyzed by in situ cooling DSC}

Figure 1 shows the DSC mean curves from multiple cooling experiments after annealing at $450{ }^{\circ} \mathrm{C}$ for $120 \mathrm{~min}$ (Setaram C600) or $60 \mathrm{~min}$ (Setaram Sensys DSC, Setaram DSC121 and Perkin Elmer Pyris Diamond DSC), respectively, over the broad dynamic range of four orders of magnitude from $0.0003 \mathrm{~K} / \mathrm{s}$ to $1 \mathrm{~K} / \mathrm{s}$ for $7003_{\text {pure. }}$ In terms of cooling durations, this means a variation of cooling from 450 to $25^{\circ} \mathrm{C}$ within a range of about 16 days to just $7 \mathrm{~min}$. The DSC curves are shifted above each other starting with the slowest cooling rate on top. For each DSC curve, its own zero level is plotted as a dotted straight line. Deviations of the DSC curve above the zero level indicate exothermic precipitation reactions. For $7003_{\text {pure, }}$ DSC reveals two main temperature regions of QIP:

- Medium-temperature precipitation (MTR) occurring in a double peak event from about $330{ }^{\circ} \mathrm{C}$ to $175^{\circ} \mathrm{C}$ and

- A very low-temperature precipitation (VLTR) from about $110{ }^{\circ} \mathrm{C}$ down to $10{ }^{\circ} \mathrm{C}$.

As seen by the decreasing peak area, which is quantified as the specific precipitation enthalpy, plotted in Fig. 3a, the MTR reactions are increasingly suppressed with increasing cooling rate. By cooling at $0.0003 \mathrm{~K} / \mathrm{s}$, the MTR releases a specific precipitation enthalpy of nearly $7 \mathrm{~J} / \mathrm{g}$. When cooling at $0.03 \mathrm{~K} / \mathrm{s}$, just a little more than $0.1 \mathrm{~J} / \mathrm{g}$ (detection limit [6]) is released, and the reactions are virtually fully suppressed at $0.1 \mathrm{~K} / \mathrm{s}$.

The precipitation enthalpy of the VLTR starting from about $3 \mathrm{~J} / \mathrm{g}$ at $0.0003 \mathrm{~K} / \mathrm{s}$ first slightly increases. During cooling at 0.001 and $0.003 \mathrm{~K} / \mathrm{s}$, the VLTR releases about $3.5 \mathrm{~J} / \mathrm{g}$. At $0.003 \mathrm{~K} / \mathrm{s}$, the MTR is already suppressed to a wide extent. This indicates that the MTR and the VLTR compete on the same alloying element atoms. At a cooling rate of $1 \mathrm{~K} / \mathrm{s}$, the VLTR in $7003_{\text {pure }}$ still releases about $0.3 \mathrm{~J} / \mathrm{g}$, i.e., from DSC, it is seen that the critical cooling rate for a complete suppression of QIP is above $1 \mathrm{~K} / \mathrm{s}$ for $7003_{\text {pure. }}$

At this point, a side aspect from the DSC methodology should be discussed: each individual DSC device has its own upper and lower cooling rate limit [6]. At cooling rates close to its upper cooling

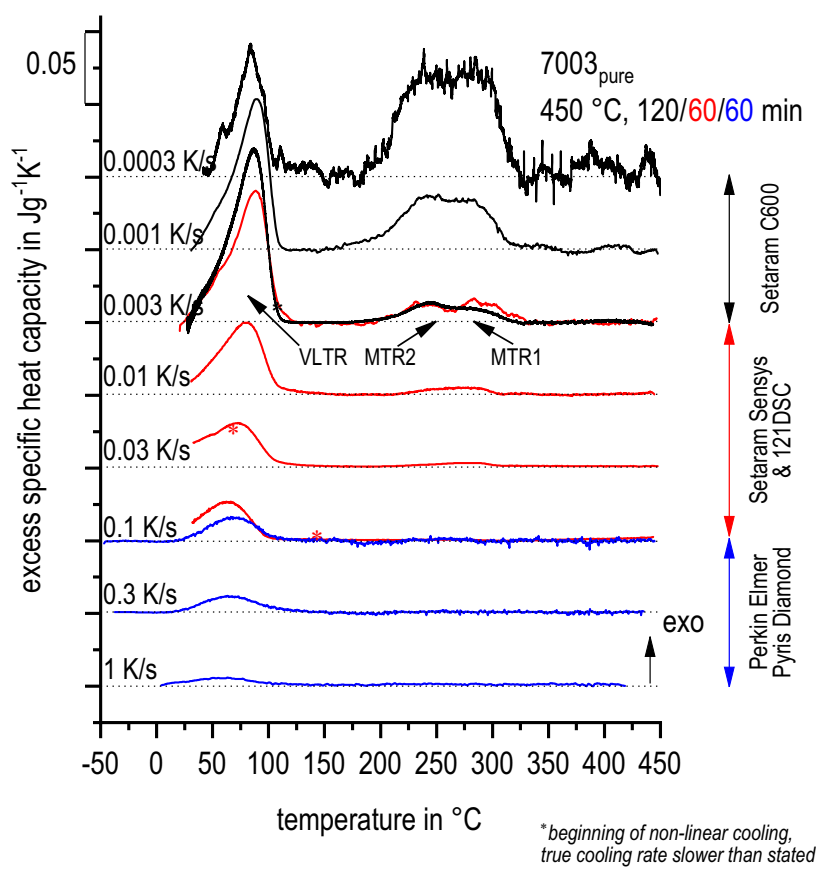

Figure 1 Selected DSC cooling curves of $7003_{\text {pure }}$ covering four orders of magnitude of cooling rates from 0.0003 to $1 \mathrm{~K} / \mathrm{s}$. 
rate limit, at a certain temperature the DSC will lose control about the programmed cooling rate and cooling will proceed slower afterward. Subsequent to this loss of control, only heat flux DSCs are still able to measure a heat flow signal. In most of our previous research (e.g. [6]), we cut off the nonlinear parts due to multiple reasons. One reason is that typically the programmed cooling rate is taken as the value for the normalization of the heat flow toward the unit of heat capacity. This normalization allows the different scanning rates to be compared. Taking the above considerations, it is a challenge to analyze the VLTR by DSC, and it is noteworthy that we, here, used the true, effective cooling rate (derivative of the sample temperature) for normalization. The temperatures where cooling switches from linear cooling to nonlinear cooling are identified by an asterisk in Figs. 1 and 2. From Fig. 1, it can be seen that we did the cooling experiments at 0.003 and $0.1 \mathrm{~K} / \mathrm{s}$ in two overlapping DSC devices. Generally, a good match of the DSC curves at rates covered by the two devices is found. The noise level is, as usual, better for the device-specific fast cooling rate. Considering the VLTR peak, the slight differences that occur between the two used DSC devices are obvious. Basically, the DSC, which loses temperature control before the VLTR, measures a higher peak maximum and peak area. This is reasonable, as the slower cooling should result in a more pronounced precipitation reaction as more time is available for the diffusion to occur. Summarizing this part of the discussion, we consider it reasonable to allow for non-linear cooling at faster cooling rates and low temperatures in heat flux DSCs in order to assess such low temperature processes like the VLTR. This might be considered for the future design of cooling DSC experiments.

Figure 2 plots the DSC cooling curves of

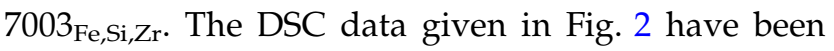
published before [17]; however, here, we re-evaluated it to present an enlarged temperature range and an improved assessment of the VLTR. The addition of $\mathrm{Fe}, \mathrm{Si}$, and $\mathrm{Zr}$ in a sum less than 0.3 at.\% obviously makes a huge impact on the QIP. This is seen from two aspects:

- Firstly, an additional high-temperature reaction HTR (about 410 to $310{ }^{\circ} \mathrm{C}$ at $0.01 \mathrm{~K} / \mathrm{s}$ ) is seen in $7003_{\mathrm{Fe}, \mathrm{Si}, \mathrm{Zr}}$. This reaction refers to the precipitation of $\beta-\mathrm{Mg}_{2} \mathrm{Si}$ [17] and, thus, is directly linked to the addition of $\mathrm{Si}$.

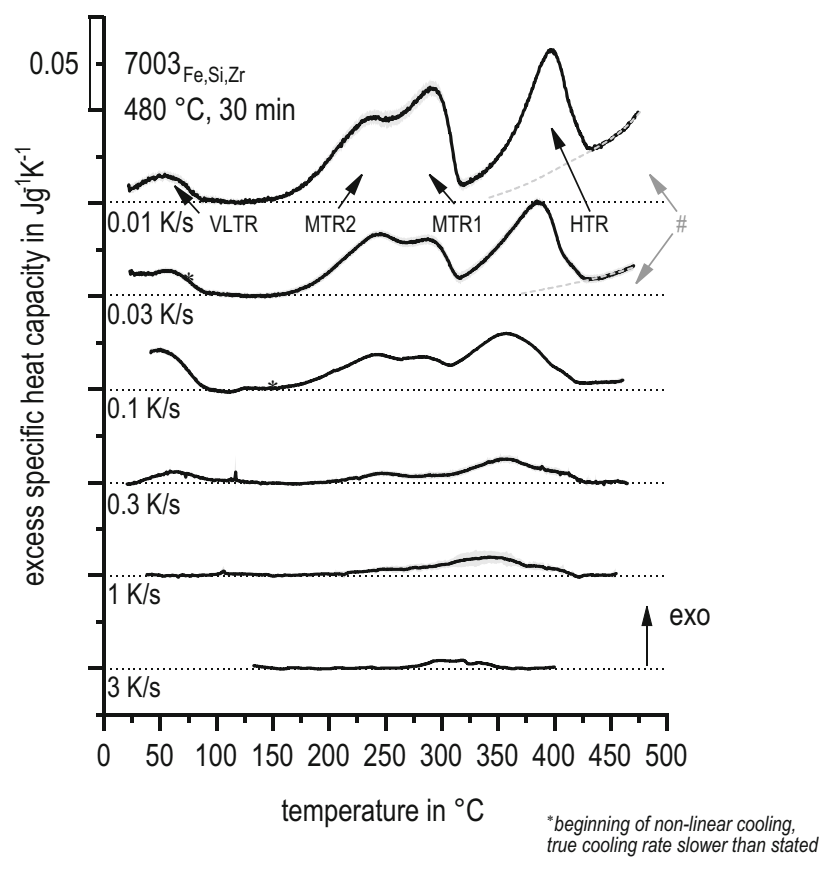

Figure 2 Selected DSC cooling curves for $7003_{\mathrm{Fe}, \mathrm{Si}, \mathrm{Zr}}$ in a range of cooling rates from 0.01 to $3 \mathrm{~K} / \mathrm{s}$.

- Secondly, it is found that in $7003_{\mathrm{Fe}, \mathrm{Si}, \mathrm{Zr}}$, the MTR are present at much faster cooling rates compared to $7003_{\text {pure, }}$ particularly also at cooling rates at which the MTR are already fully suppressed in $7003_{\text {pure }}$.

Next to these differences, there are also some aspects of QIP that are highly similar for both variants of 7003: the MTR is seen as double peak events

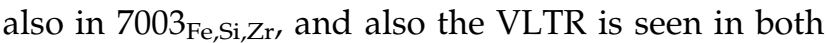
alloys. The addition of $\mathrm{Fe}$ and $\mathrm{Si}$ adds coarse intermetallic particles enriched in $\mathrm{Al}, \mathrm{Si}$, and $\mathrm{Fe}$ [17], which likely form as primary particles in the melt. Those types of intermetallic particles are known to act as nucleation sites for coarse equilibrium phase QIP at high temperatures for a broad range of tech-

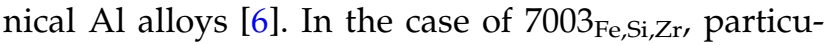
larly $\beta-\mathrm{Mg}_{2} \mathrm{Si}$ nucleates on these coarse Al-Si-Fe-rich intermetallics [17]. Beyond that, the addition of $\mathrm{Zr}$ results in the formation of $\mathrm{Al}_{3} \mathrm{Zr}$ dispersoids in $7003_{\mathrm{Fe}, \mathrm{Si}, \mathrm{Zr}}$ [17], obviously leading to an acceleration of QIP at temperatures above $200{ }^{\circ} \mathrm{C}$. As a result, the VLTR is much less pronounced in $7003_{\mathrm{Fe}, \mathrm{Si}, \mathrm{Zr}} \mathrm{com}-$ pared to $7003_{\text {pure }}$. Such VLTR has also been reported earlier for other AlZnMg alloys like AA7020 and AA7021 [21, 22], and hints for such a VLTR have also been found for higher concentrated $\mathrm{AlZnMgCu}$ alloys [6, 21]. However, as all of the latter are 
Figure $37003_{\text {pure }}$ a hardness after cooling and specific precipitation enthalpy as a function of cooling rate, b hardness as a function of cooling rate at various natural aging durations as well as after artificial aging at $120^{\circ} \mathrm{C}$ for $24 \mathrm{~h}$.
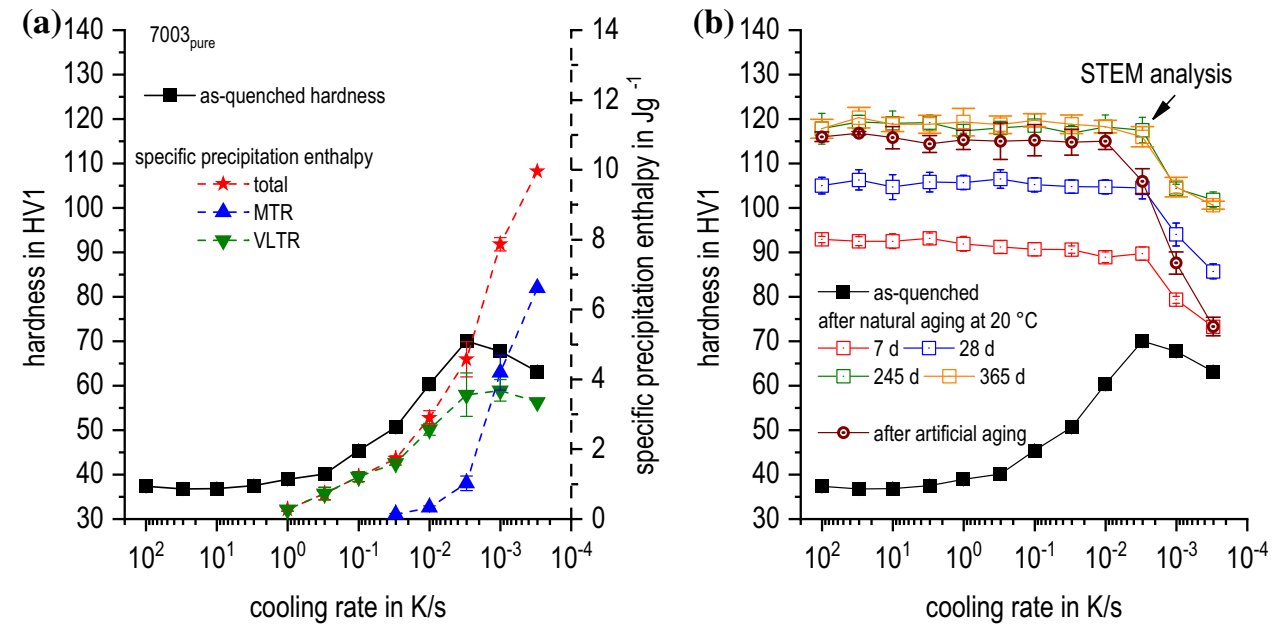

Figure $47003_{\mathrm{Fe}, \mathrm{Si}, \mathrm{Zr}}$ a hardness after cooling and specific precipitation enthalpy as a function of cooling rate, $\mathbf{b}$ hardness as a function of cooling rate at various natural aging durations as well as after artificial aging at $120{ }^{\circ} \mathrm{C}$ for $24 \mathrm{~h}$.

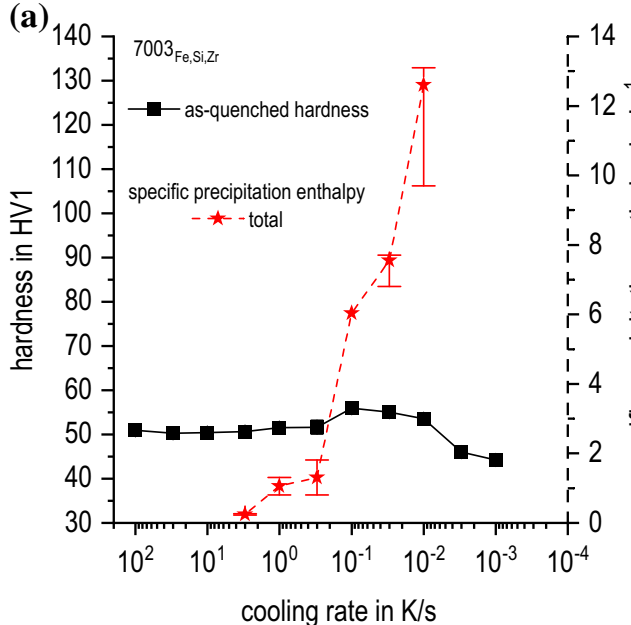

(b)

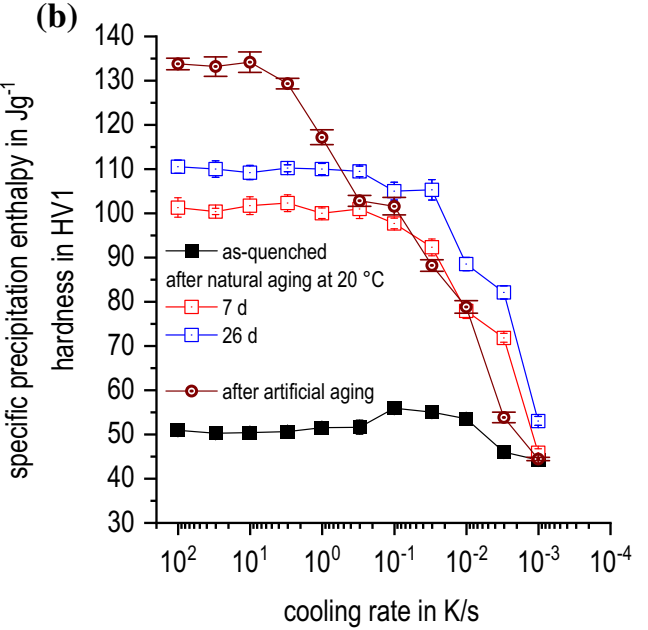

technical alloys and particularly contain dispersoids forming elements, such a pronounced VLTR has never been seen as in $7003_{\text {pure }}$.

Also, in Fig. 2, one further aspect of the DSC methodology must be discussed: It is seen that the DSC signal at slow cooling does not start at the zero level (marked by a hash). This might be related to two different aspects: Either it could indicate a real instant precipitation reaction [19] or it might be related to a metrological DSC artifact. The latter might result from e.g., a slight variance in the surface color of the used DSC crucibles [6]. At high temperatures, part of the heat between the sensor and sample is exchanged by radiation. The surface color of the used crucibles influences the radiation emission and uptake of the sample. Here, we refrain from going deeper into this, as it does not influence the main conclusions.

\section{Hardness and aging behavior}

Figure 3a plots the specific precipitation enthalpies (integrated DSC peak areas) of the MTR and the VLTR separately as well as in total for $7003_{\text {pure }}$. Figure $3 b$ shows the hardness in the as-quenched condition, in naturally aged conditions after various aging durations, and after artificial aging $\left(20^{\circ} \mathrm{C}\right.$ for $15 \mathrm{~min}+120{ }^{\circ} \mathrm{C}$ for $24 \mathrm{~h}$ ).

From the as-quenched hardness in Fig. 3a, a substantial increase in hardness due to QIP is seen at rates of about 3 to 4 orders of magnitude below the full suppression of QIP. The maximum hardness in the as-quenched condition is found after cooling at $0.003 \mathrm{~K} / \mathrm{s}$ to be about $70 \mathrm{HV} 1$. At this cooling rate, the precipitation enthalpy of VLTR is about at its maximum, while the MTR is already suppressed to a great extent. As the precipitation enthalpy is proportional to the volume fraction precipitated by a 

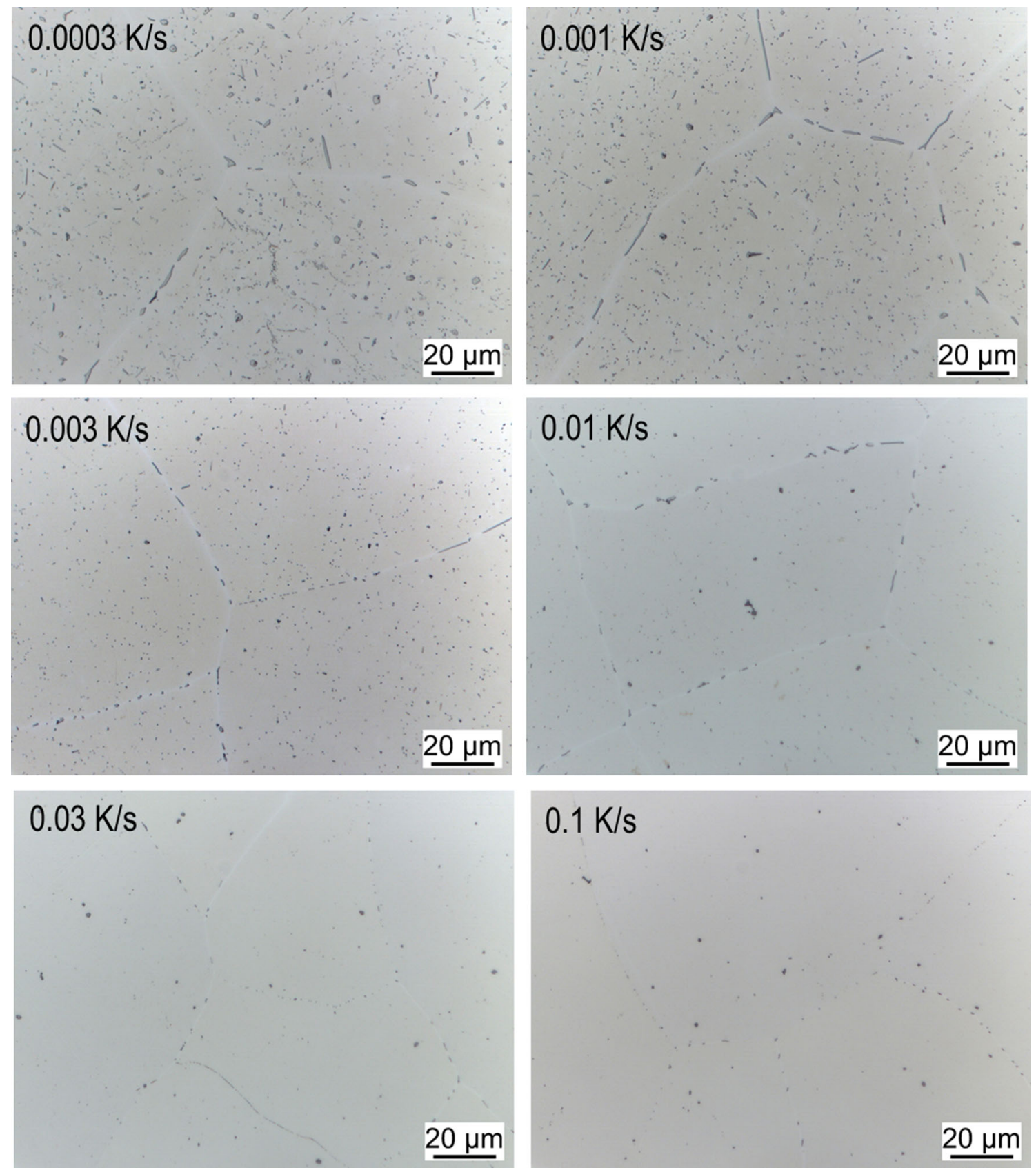

Figure 5 Images from optical microscopy after continuous cooling of $7003_{\text {pure }}$ at various rates; etched with Weck's reagent (4 s).

certain reaction, it can be concluded that at a cooling rate of $0.003 \mathrm{~K} / \mathrm{s}$, a substantial fraction of precipitates is formed during the VLTR, which gives a direct hardening effect. The as-quenched hardness from $0.003 \mathrm{~K} / \mathrm{s}$ toward faster cooling is decreasing due to an increasing suppression of the VLTR, which is also seen from the DSC curves and the evaluated precipitation enthalpy. The hardness in the as-quenched condition reaches a constant minimum level of about $37 \mathrm{HV} 1 \mathrm{for}$ cooling at $10 \mathrm{~K} / \mathrm{s}$ or faster. We conclude from that on a physical upper critical cooling rate (uCCR), which is the minimum cooling rate to achieve a complete suppression of any QIP of $10 \mathrm{~K} / \mathrm{s}$. That is a fully supersaturated solid solution is achieved after quenching with $10 \mathrm{~K} / \mathrm{s}$ or faster only.

Considering the hardness after additional natural aging (Fig. 3 b), from slowest toward faster cooling, a steep increase is seen until the cooling rate of $0.003 \mathrm{~K} / \mathrm{s}$, at which the hardness in the as-quenched condition reached its maximum. At faster rates, the 
Figure 6 Highlighting some specific features of coarse quench-induced precipitates in $7003_{\text {pure }}$ cooled at $0.001 \mathrm{~K} / \mathrm{s}$.

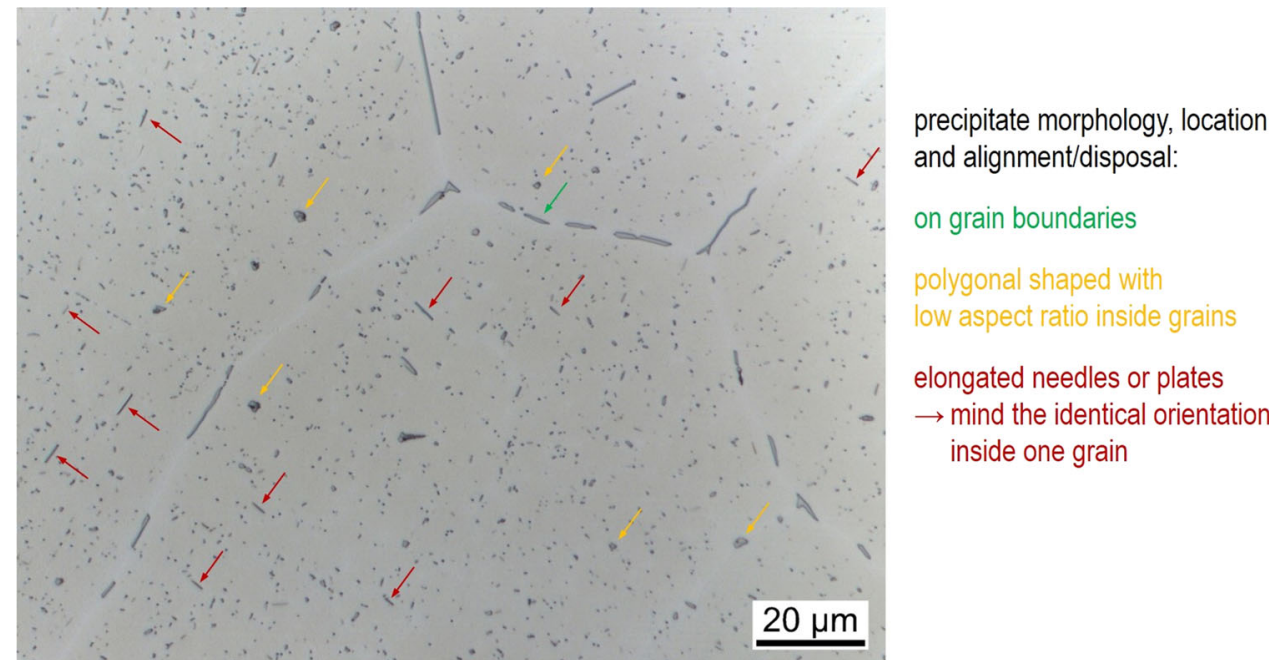

hardness remains at about a constant level, which increases with prolonged duration of natural aging. After 245 days, the full aging potential of about $120 \mathrm{HV} 1$ seems to be achieved. The hardness after $15 \mathrm{~min}$ of natural pre-aging at $20^{\circ} \mathrm{C}$ and subsequent artificial aging at $120^{\circ} \mathrm{C}$ for $24 \mathrm{~h}$ shows a similar behavior. Interestingly, the hardness level is slightly lower than after prolonged natural aging and, in particular, is only reached for cooling at $0.01 \mathrm{~K} / \mathrm{s}$ or faster.

Figure 4 shows the precipitation enthalpy as well as the hardness after natural and artificial aging as a

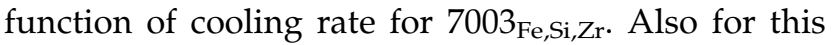
alloy, a slight peak in the as-quenched hardness is found. It is located at cooling rates about 0.01 to $0.1 \mathrm{~K} / \mathrm{s}$, at which DSC indicates the maximum of the VLTR. However, the direct hardening effect of the QIP here is way smaller compared to $7003_{\text {pure. The }}$ hardness after natural aging shows a saturation level for cooling at $0.1 \mathrm{~K} / \mathrm{s}$ and faster. The saturation plateau for hardness after artificial aging is only reached by cooling at $10 \mathrm{~K} / \mathrm{s}$ or faster. That is, for $7003_{\mathrm{Fe}, \mathrm{Si}, \mathrm{Zr}}$, QIP causes negative effects in any case considering the hardness after artificial aging. In contrast, for $7003_{\text {pure, }}$ QIP has virtually no detrimental effect on the hardness for a wide range of cooling rates. The substantial difference can largely be attributed to the acceleration of QIP by the addition of $\mathrm{Fe}, \mathrm{Si}$, and $\mathrm{Zr}$ and, thereby, the addition of coarser heterogeneous nucleation sites.

A basically similar direct aging effect of quenchinduced precipitates has previously been found in $\mathrm{AlZnMgCu}$ alloys [23-25]. The high aspect ratio $\mathrm{Y}$ phase platelets, enriched in $\mathrm{Cu}$ and $\mathrm{Zn}$, was found to contribute about 50 to $100 \mathrm{MPa}$ to the ultimate tensile strength in certain conditions slower cooled than the alloy specific uCCR of $300 \mathrm{~K} / \mathrm{s}$. In [23], it was revealed that the $\mathrm{Y}$ phase is related to precipitation during cooling in a temperature range of about 270 to $150{ }^{\circ} \mathrm{C}$, which is much higher compared to the VLTR seen in the case of $7003_{\text {pure }}$. It is thus likely that the direct hardening effect of quench induced precipitation seen in 7003 is caused by another type of phase.

One important general aspect of precipitation during age hardening should be addressed: according to text-book knowledge (e.g. [3, 26]), quenched-in and, thereby, supersaturated vacancies play an important role for the diffusive mass-transport during the process of precipitation. From this work, it can be seen that precipitation during natural aging after very slow cooling has a very similar kinetic behavior compared to a preceding fast quenching. This raises the question of whether a certain critical cooling rate specifically valid for the supersaturation of the matrix by quenched-in vacancies exists. However, the aspect of the kinetics of vacancy supersaturation by quenching is not sufficiently understood and should be analyzed in future work.

\section{Micro- and nanostructure}

Figure 5 gives an overview on the QIP visible in OM for $7003_{\text {pure }}$ at various cooling rates ranging from 0.0003 to $0.1 \mathrm{~K} / \mathrm{s}$. It can be seen that the coarse precipitates formed during cooling decrease in size with increasing cooling rate. At slow cooling rates, the precipitates grow to sizes of a few microns and even up to few tens of microns at grain boundaries. 

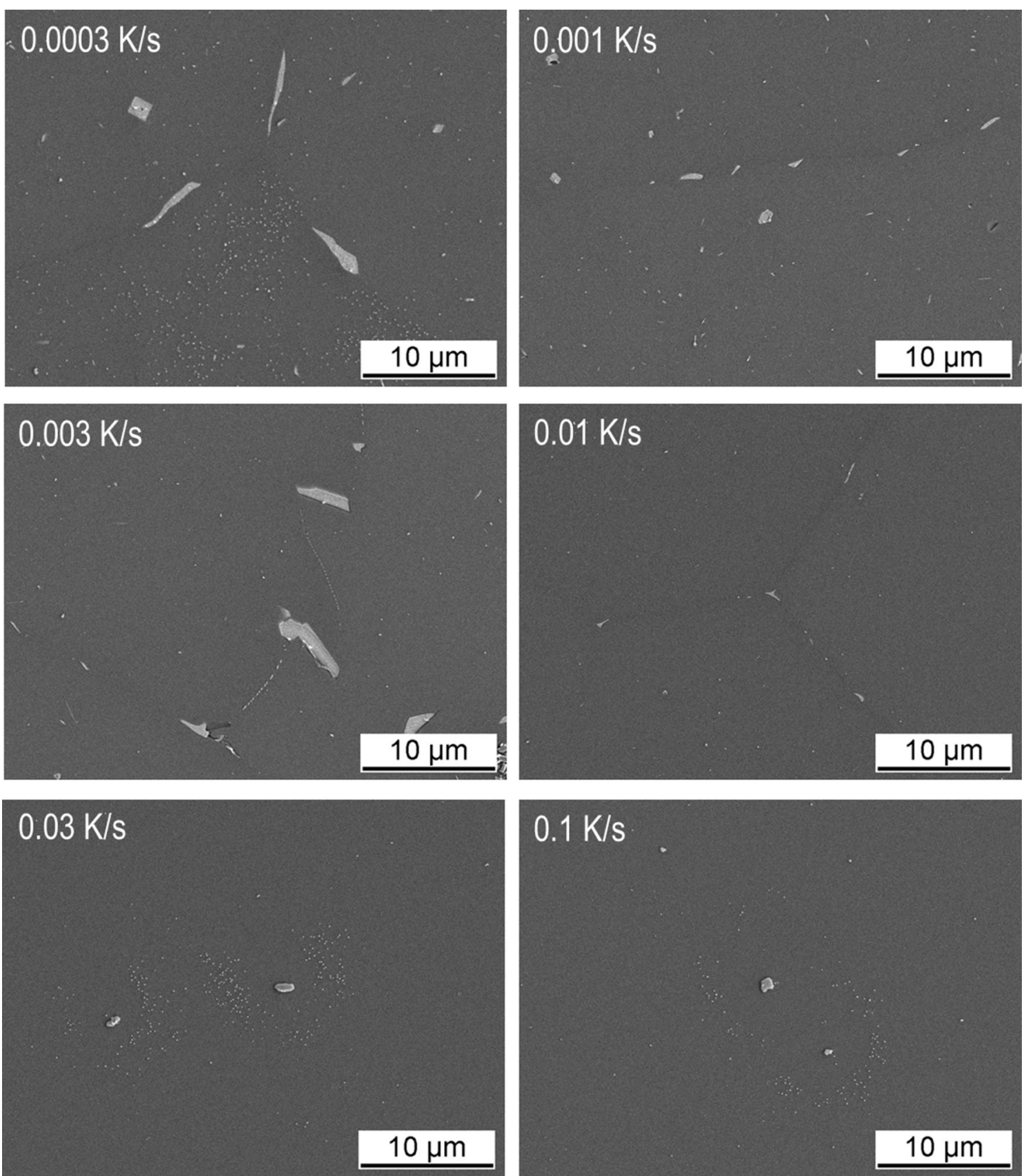

$0.1 \mathrm{~K} / \mathrm{s}$

Figure 7 SEM secondary electron images after continuous cooling of $7003_{\text {pure }}$ at various rates.

Figure 6 highlights some distinct features of coarser quench induced precipitate particles, their location, and morphology. As common for most $\mathrm{Al}$ alloys [6], coarser quench induced precipitates are present at grain boundaries and inside the grains much more frequently. Inside the grains, QIP occurs in two distinct morphologies: polygonal precipitates with a low aspect ratio as well as elongated rods (which potentially are plates), which have much larger aspect ratios. The rod-shaped particles appear to grow in distinct directions of the $\mathrm{Al}$ matrix lattice, as they often are seen parallel or perpendicular to each other within one specific grain.

With the increased magnification of scanning electron microscopy, some smaller precipitates (submicrometer scale) next to the coarse precipitates ( $\mu \mathrm{m}$ scale) can be seen in the grain interior, which particularly holds for the slowest investigated cooling 

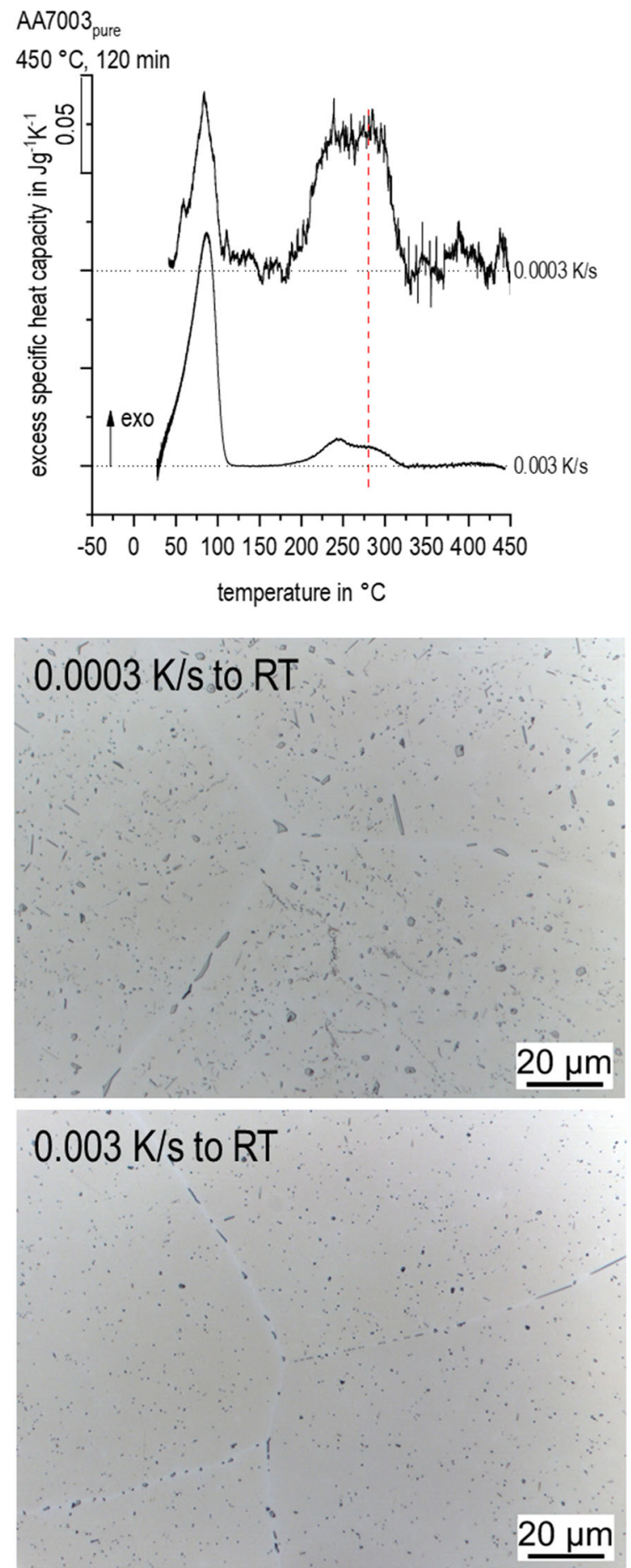
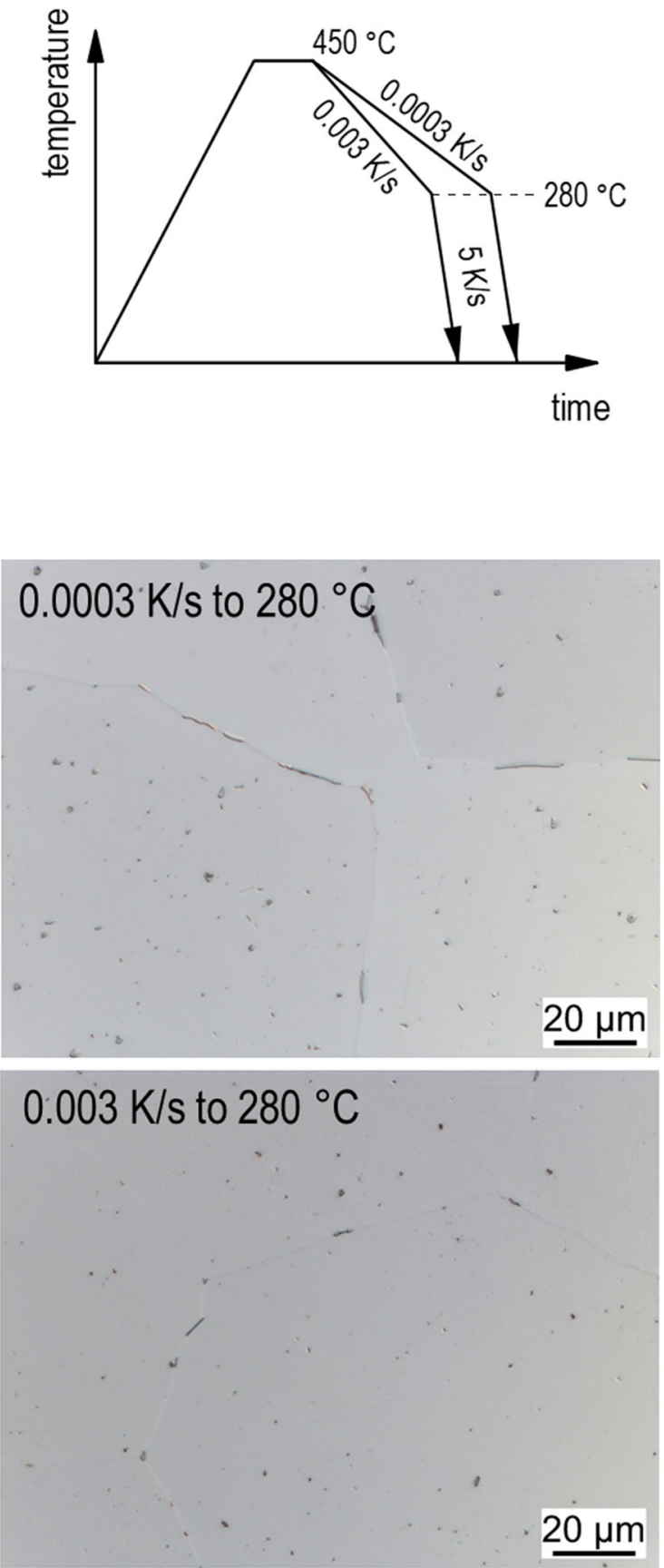

Figure 8 Interrupted quenching method and images from optical microscopy of $7003_{\text {pure }}$ after interrupted quenching method; etched with Weck's reagent (4 s).

condition of $0.0003 \mathrm{~K} / \mathrm{s}$ (see Fig. 7). They are hardly seen at faster cooling rates in SEM. On samples cooled at 0.03 and $0.1 \mathrm{~K} / \mathrm{s}$, it appears that this finer level of QIP is localized. Particularly around the coarse QIP, a depletion of such finer particles is seen, giving an impression of the area or depleted concentration of the alloying element atoms resulting from the diffusion field from which the coarse particles have grown. The radius of the diffusion field is on the order of a few microns at 0.03 and $0.1 \mathrm{~K} / \mathrm{s}$. 

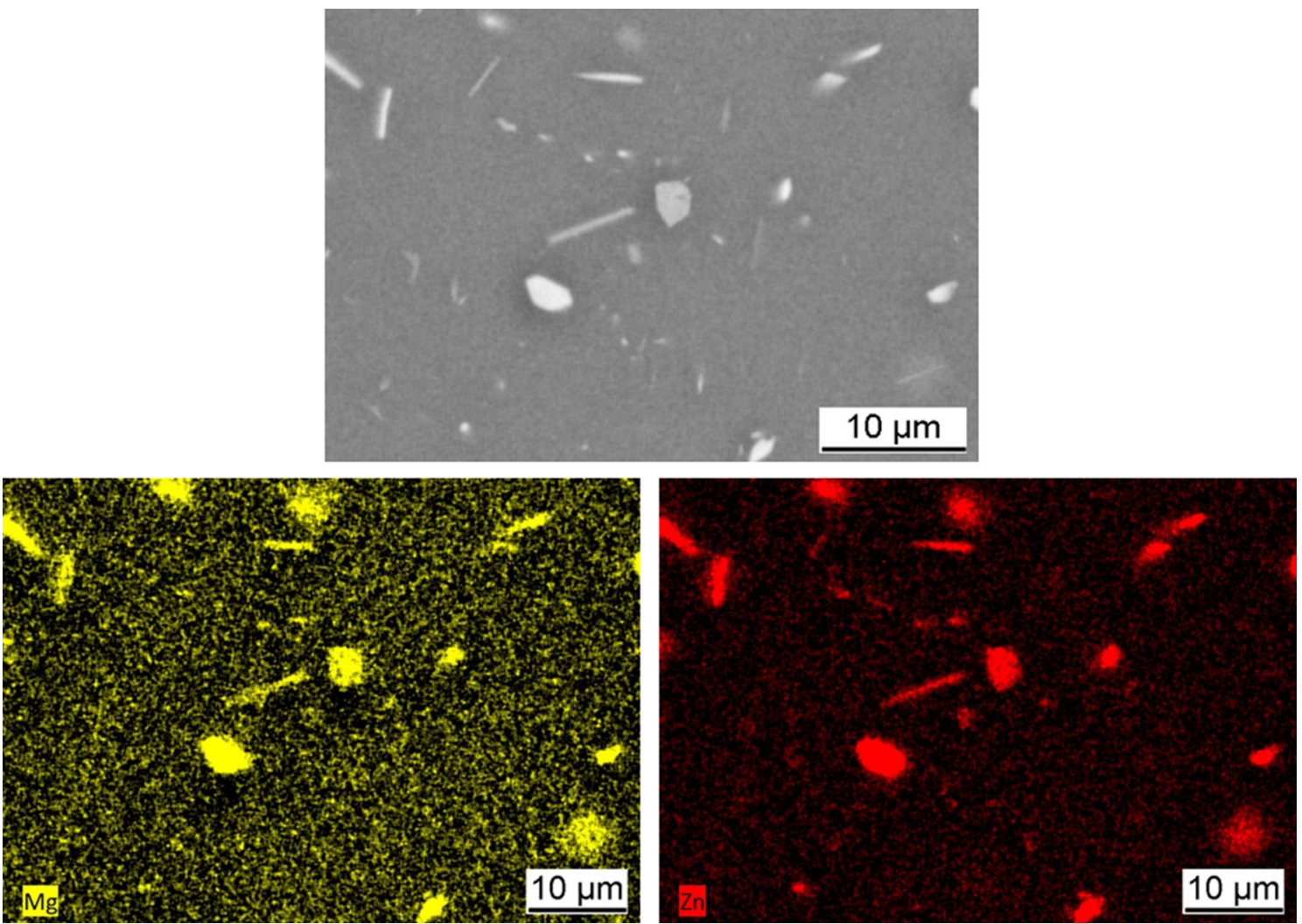

Figure 9 SEM SE image and corresponding EDS-maps of the $\mathrm{Zn}$ and $\mathrm{Mg}$ distribution in coarse quenched induced precipitates in $7003_{\text {pure }}$ after slow cooling at $0.0003 \mathrm{~K} / \mathrm{s}$.

To gain more evidence of which types of particles grow during the precipitation events in DSC, some slow cooling experiments were interrupted shortly after the first peak of the MTR is passed (see the schematic illustration in Fig. 8). Samples were cooled slowly until $280{ }^{\circ} \mathrm{C}$ followed by an overcritical quenching at $5 \mathrm{~K} / \mathrm{s}$ (overcritical in terms of the MTR). From the OM images, it can be seen that the higher temperature part of the double MTR peak refers to grain boundary precipitation and precipitation of low aspect ratio particles inside the grain. The elongated particles with a larger aspect ratio are precipitating primarily during the lower temperature part of the MTR. However, it is obvious that both parts are greatly overlapping. A very similar precipitation behavior has been reported earlier for the QIP of diamond cubic Si in a pure binary Al0.72Si alloy. In that case, $\mathrm{Si}$ at higher temperatures precipitated as polygonal particles with a low aspect ratio, while the same phase precipitated as thin plates with a largely increased aspect ratio at lower temperatures $[6,27]$.
The SEM-EDS in Fig. 9 clearly indicates an enrichment in $\mathrm{Mg}$ and $\mathrm{Zn}$ for all types of coarse QIP from slow cooling at $0.0003 \mathrm{~K} / \mathrm{s}$. Additional XRD analysis (spectra not shown) of a sample cooled at the same rate gives evidence for the presence of the $\mathrm{MgZn}_{2}$ phase, which might contain different $\mathrm{Al}$ content, as has been discussed in several studies $[28,29]$.

STEM analysis was done on a $7003_{\text {pure }}$ sample cooled at $0.003 \mathrm{~K} / \mathrm{s}$ to room temperature. The cooled sample was aged at room temperature for about 9 months before a TEM foil was prepared from it. From the HAADF-STEM images in Fig. 10, an enormous number density of nanoparticles is seen. The nanoparticles appear globular, and their diameters are found to be about 2 to $4 \mathrm{~nm}$. STEM-EDS revealed an enrichment in $\mathrm{Zn}$ and $\mathrm{Mg}$ also for the clusters, while $\mathrm{Al}$ is depleted. As the sample was naturally aged for some months prior to the TEM foil preparation, the structures seen are a result of cooling and aging. However, as the hardness directly after cooling shows a peak, one can assume that they have partly grown during cooling. 
Figure 10 a, b HAADFSTEM images indicating an enormous number density of nanoparticles after cooling at $0.003 \mathrm{~K} / \mathrm{s}$ and natural aging for about 9 months. c Relative atomic composition from EDS comparing only the elements $\mathrm{Al}, \mathrm{Mg}$, and $\mathrm{Zn}$ of the two areas highlighted in $\mathbf{b}$ indicating a clear enrichment of the clusters in $\mathrm{Mg}$ and particularly in $\mathrm{Zn}$.
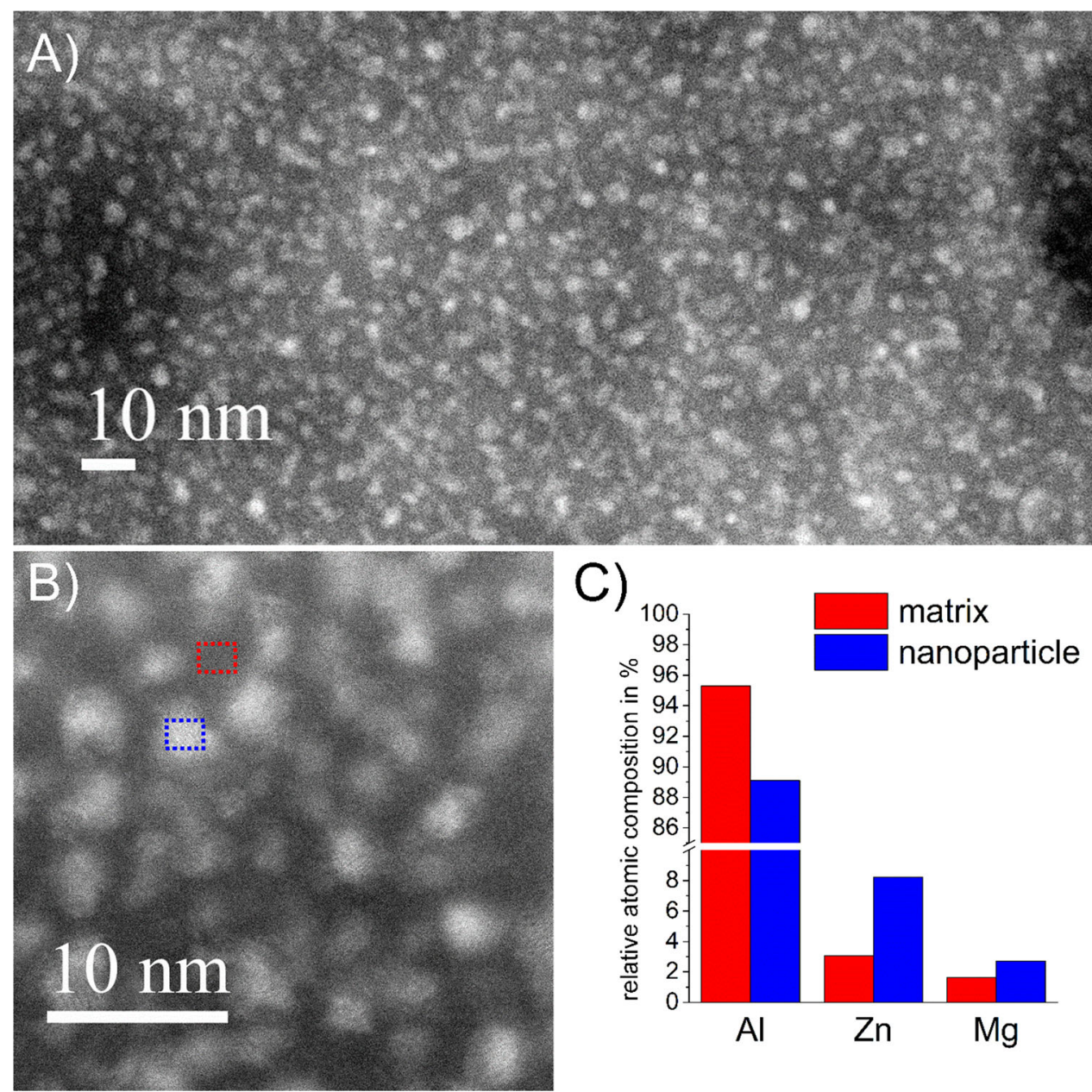

As a summarizing result, a continuous cooling precipitation diagram for $7003_{\text {pure }}$ can be constructed from the DSC, hardness, and microstructures (Fig. 11). The separation of the double peak during the medium temperature reaction is plotted with a dashed line, as it is hard to determine due to the overlap of the two reactions involved. Additionally, the uCCR of the very low temperature reaction is estimated by the hardness results for a cooling rate of $10 \mathrm{~K} / \mathrm{s}$. That is, when the hardness after artificial aging does not increase with increasing cooling rate, the very low temperature reaction should be suppressed completely.

The continuous cooling precipitation diagram for $7003_{\mathrm{Fe}, \mathrm{Si}, \mathrm{Zr}}$ is shown in Fig. 12. It contains $\mathrm{Mg}_{2} \mathrm{Si}$ precipitation as a further HTR. Only clearly determinable reactions were drawn with a solid line. Uncertain reaction temperatures due to the severe overlap were plotted as a dashed line.
Figure 13 compares the total specific precipitation enthalpies released during cooling and the hardness after subsequent aging for four $\mathrm{AlZnMg}(\mathrm{Cu})$ alloys. These four alloys are largely different in the concentration of the main alloying elements as well as elements forming primary precipitates and dispersoids (for details on the alloys 7085 lowCu $_{\text {and 7075 }}$ see Refs. $[6,30])$. Therefore, the amount of nucleation sites for coarse heterogeneous nucleation of quench-induced precipitation differs. It is seen that the alloy 7075 I might lead to maximum possible hardness values, but this is only true if very fast cooling at about $300 \mathrm{~K} / \mathrm{s}$ can be applied. $7085_{\mathrm{lowCu}}$ and especially $7003_{\text {pure }}$ come along with slower precipitation kinetics during quenching, which results in higher strength at lower cooling rate ranges. This might be important if the cooling rate is restricted due to technological reasons (thick components or for distortion control). 
Figure 11 Continuous cooling precipitation diagram of $7003_{\text {pure. }}$

Figure 12 Continuous cooling precipitation diagram of $7003_{\mathrm{Fe}, \mathrm{Si}, \mathrm{Zr}}$.
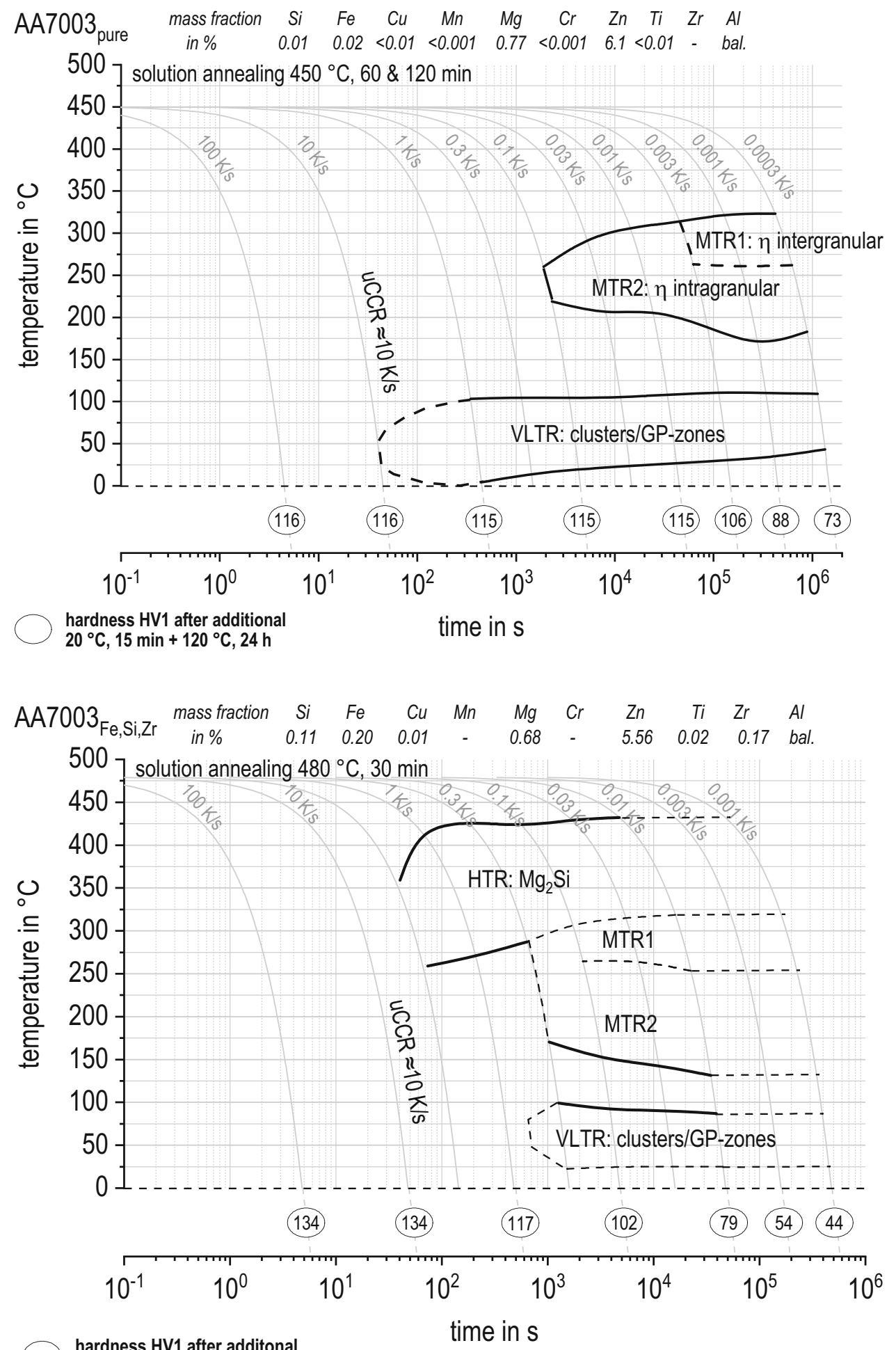

by optical and electron microscopy on an AlZn6Mg0.75 alloy without $\left(7003_{\text {pure }}\right)$ and with minor additions of $\mathrm{Fe}, \mathrm{Si}$, and $\mathrm{Zr}\left(7003_{\mathrm{Fe}, \mathrm{Si}, \mathrm{Zr}}\right)$, we conclude the following: 

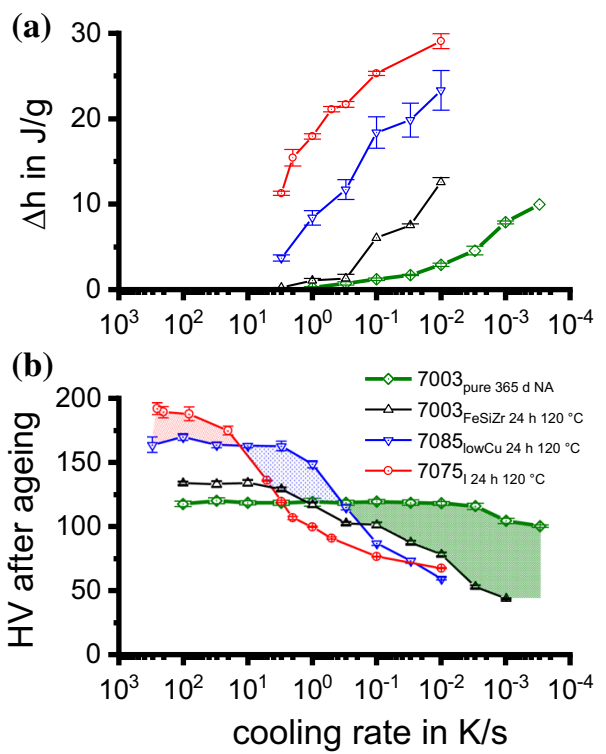

Figure 13 a Specific total precipitation enthalpy during cooling from solution treatment and $\mathbf{b}$ hardness after cooling and subsequent aging for four different $\operatorname{AlZnMg}(\mathrm{Cu})$ alloys over a broad range of cooling rates. The data of 7075 I and 7085 have been taken from literature $[6,30]$.

- Quench induced precipitation (QIP) in $7003_{\text {pure }}$ happens in two distinct main reaction temperature regions: a medium temperature reaction (MTR, about $330{ }^{\circ} \mathrm{C}$ to $175^{\circ} \mathrm{C}$ ) and a very low temperature reaction (VLTR, about $110{ }^{\circ} \mathrm{C}$ to $10{ }^{\circ} \mathrm{C}$ ); for cooling rates faster than $0.003 \mathrm{~K} / \mathrm{s}$, the majority of the transformed enthalpy is released by the VLTR. Such a VLTR has been seen for other alloys before, but is much more pronounced in this alloy.

- Small additions of $\mathrm{Fe}, \mathrm{Si}$, and $\mathrm{Zr}$ (in sum less than 0.3 at.\%) have a severe influence on the QIP: the addition of $\mathrm{Si}$ adds the sequence of $\mathrm{Mg}_{2} \mathrm{Si}$ seen as an additional high temperature reaction in the DSC for $7003_{\mathrm{Fe}, \mathrm{Si}, \mathrm{Zr}}$. and by adding additional nucleation sites (as coarsepotentially primary $\mathrm{Fe}-$, Si-rich intermetallics or as $\mathrm{Al}_{3} \mathrm{Zr}$-dispersoids). In particular, the $\mathrm{Al}_{3} \mathrm{Zr}$ dispersoids, which were already previously known as nucleation sites for the QIP of the $\eta-\mathrm{Mg}(\mathrm{Zn}, \mathrm{Al})_{2}$ phase, accelerate its precipitation and, thus, substantially increase the quench sensitivity.

- The MTR originates from the superposition of two largely overlapping reactions. It is most likely that these different contributions originate from the precipitation of the same $\eta-\mathrm{Mg}(\mathrm{Zn}, \mathrm{Al})_{2}$-phase precipitating from different nucleation sites and in different morphologies. At slightly higher temperatures, the $\eta-\mathrm{Mg}(\mathrm{Zn}, \mathrm{Al})_{2}$-phase precipitates on grain boundaries and inside the grains as polygonal shaped particles with a low aspect ratio. At slightly lower temperatures, precipitation of the $\eta-\mathrm{Mg}(\mathrm{Zn}, \mathrm{Al})_{2}$-phase occurs in rod-shaped particles with a largely increased aspect ratio. In all cases, the $\eta-\mathrm{Mg}(\mathrm{Zn}, \mathrm{Al})_{2}$-phase particles reach dimensions ranging from several tens of microns down to some hundreds of nm depending on the cooling rate.

- The VLTR refers to the formation of a huge particle number density of nanoparticles. Those apparently are globular with a diameter of about 3 to $5 \mathrm{~nm}$ after cooling at $0.003 \mathrm{~K} / \mathrm{s}$ and additional natural aging for some months. Those quenchedin nanoparticles gain a substantial direct hardening contribution, and the hardness in the asquenched condition shows a maximum at $0.003 \mathrm{~K} / \mathrm{s}$.

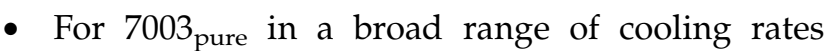
$(0.003$ to $10 \mathrm{~K} / \mathrm{s})$, the QIP is found to cause no negative effect on the hardness after natural aging. For this alloy, the hardness after natural aging for 9 month or longer is found to be on the saturation level of about $120 \mathrm{HV} 1$ for cooling rates above $0.003 \mathrm{~K} / \mathrm{s}$ (i.e., cooling durations shorter than about $40 \mathrm{~h}$ ). Therefore, for this alloy, we distinguish a technical critical cooling rate (tCCR, in terms of hardness) to be $0.003 \mathrm{~K} / \mathrm{s}$, while a full supersaturation of the solid solution is reached with the physical upper critical cooling rate of $10 \mathrm{~K} / \mathrm{s}$.

\section{Acknowledgements}

The Jeol NeoARM STEM was funded by the German Research Foundation (Deutsche Forschungsgemeinschaft) DFG INST 264/161-1 FUGG.

Dr. Carsten Kreyenschulte and Dr. Markus Frank are gratefully acknowledged for their help with the electron microscopy analysis and related discussions.

\section{Author contribution}

$\mathrm{BM}$ and CR conceived the experimental plan. MMN produced the material under the guidance of $\mathrm{HY}$ and KY; CR did the DSC analysis; AS did the SEM 
analysis; $\mathrm{KO}$ and $\mathrm{BM}$ did the STEM analysis; all authors contributed to the discussion of the data. BM and CR wrote the raw manuscript; OK did the final revision. All authors approved the final version of the manuscript.

\section{Funding}

Open Access funding enabled and organized by Projekt DEAL.

\section{Declarations}

Conflicts of Interest The authors declare no conflict of interest.

Open Access This article is licensed under a Creative Commons Attribution 4.0 International License, which permits use, sharing, adaptation, distribution and reproduction in any medium or format, as long as you give appropriate credit to the original author(s) and the source, provide a link to the Creative Commons licence, and indicate if changes were made. The images or other third party material in this article are included in the article's Creative Commons licence, unless indicated otherwise in a credit line to the material. If material is not included in the article's Creative Commons licence and your intended use is not permitted by statutory regulation or exceeds the permitted use, you will need to obtain permission directly from the copyright holder. To view a copy of this licence, visit http://creativecommons.org/licen ses/by/4.0/.

\section{References}

[1] Dursun T, Soutis C (2014) Recent developments in advanced aircraft aluminium alloys. Mater Des 1980-2015(56):862-871. https://doi.org/10.1016/j.matdes.2 013.12 .002

[2] Shin J, Kim T, Kim D, Kim D, Kim K (2017) Castability and mechanical properties of new $7 \mathrm{xxx}$ aluminum alloys for automotive chassis/body applications. J Alloys Compd 698:577-590. https://doi.org/10.1016/j.jallcom.2016.12.269

[3] Polmear IJ (2006) Light alloys: from traditional alloys to nanocrystals, 4th edn. Elsevier Butterworth-Heinemann, Amsterdam

[4] Rometsch PA, Zhang Y, Knight S (2014) Heat treatment of $7 \mathrm{xxx}$ series aluminium alloys - Some recent developments.
Trans Nonferrous Met Soc China 24(7):2003-2017. https://d oi.org/10.1016/S1003-6326(14)63306-9

[5] Strobel K, Easton MA, Sweet L, Couper MJ, Nie JF (2011) Relating quench sensitivity to microstructure in 6000 series aluminium alloys. Mater Trans 52(5):914-919

[6] Milkereit B, Starink MJ, Rometsch PA, Schick C, Kessler O (2019) Review of the quench sensitivity of aluminium alloys: analysis of the kinetics and nature of quench-induced precipitation. Materials 12(24). https://doi.org/10.3390/ma 12244083

[7] Yoshida H (2010) Alloy development for transportation in Sumitomo Light Metal In: Proceedings 12th international conference on aluminium alloys. The Japan Institute of Light Metals: 54-61., Yokohama, Japan

[8] Baba Y (1967) Influence of additional elements on the quench-sensitivity and nucleation of precipitates in Al-ZnMg alloys. J Jpn Inst Met 31(7):910-915. https://doi.org/10. 2320/jinstmet1952.31.7_910

[9] Baba Y (1970) Effects of additional elements and heat treatments on the fracture characteristics of $\mathrm{Al}-\mathrm{Zn}-\mathrm{Mg}$ alloy. Trans JIM 11(6):404-410. https://doi.org/10.2320/matertran s1960.11.404

[10] Baba Y, Yoshida H (1977) Recent development of 7003 extrusion alloy. Proceed Second Int Aluminum Extrusion Technol Semin 1:301-306

[11] Baba Y, Fukui T., Takashima A., Terai S. (1975) Newly developed Al-Zn-Mg alloys containing less Magnesium and their application to transport industry In: 6 th international conference on light metals-Leoben/Vienna: 99-101, pp 99-101

[12] Baba Y, Fukui T, Takashima A (1974) Study on newly developed Al-Zn-Mg alloys containing less Mg. J Japan Inst Light Metals 24(1):25-35. https://doi.org/10.2464/jilm.24.25

[13] Baba Y (2000) Review and prospect on technical development of aluminum. Sumitomo Light Metal Tech Rep 41(1):91-121

[14] Yoshida H, Baba Y (1981) Role of zirconium to improving strength and stress-corrosion resistance of $\mathrm{Al}-\mathrm{Zn}-\mathrm{Mg}$ and $\mathrm{Al}-$ $\mathrm{Zn}-\mathrm{Mg}-\mathrm{Cu}$ alloys. J Japan Inst Light Metals 31(1):20-29. h ttps://doi.org/10.2464/jilm.31.20

[15] Zhang Y, Bettles C, Rometsch PA (2014) Effect of recrystallisation on Al3Zr dispersoid behaviour in thick plates of aluminium alloy AA7150. J Mater Sci 49(4):1709-1715. h ttps://doi.org/10.1007/s10853-013-7856-x

[16] Pan T-A, Tzeng Y-C, Bor H-Y, Liu K-H, Lee S-L (2021) Effects of the coherency of Al3Zr on the microstructures and quench sensitivity of Al- $\mathrm{Zn}-\mathrm{Mg}-\mathrm{Cu}$ alloys. Materials Today Communications:102611. Doi:https://doi.org/10.1016/j.mtc omm.2021.102611 
[17] Lervik A, Marioara CD, Kadanik M, Walmsley JC, Milkereit B, Holmestad R (2020) Precipitation in an extruded AA7003 aluminium alloy: observations of 6xxx-type hardening phases. Mater Des 186(108204)

[18] Yoshida H, Watanabe T, Hatta H (2018) Effect of quenching rate on age hardening in an $\mathrm{Al}-\mathrm{Zn}-\mathrm{Mg}$ alloy sheet In: Mary Wells MB (ed) 16th International Conference on Aluminium Alloys, Montreal, Canada. METSOC.org, paper 393778

[19] Kemsies RH, Milkereit B, Wenner S, Holmestad R, Kessler O (2018) In situ DSC investigation into the kinetics and microstructure of dispersoid formation in Al-Mn-Fe-Si(-Mg) alloys. Mater Des 146:96-107. https://doi.org/10.1016/j.ma tdes.2018.03.007

[20] Weck E, Leistner E (1986) Metallographische Anleitung zum Farbätzen nach dem Tauchverfahren Teil III: Nichteisenmetalle, Hartmetalle und Eisenwerkstoffe. Deutscher Verlag für Schweisstechnik, Düsseldorf, Nickel-Basisund Kobalt-Basis-Legierungen

[21] Zhang Y, Milkereit B, Kessler O, Schick C, Rometsch PA (2014) Development of continuous cooling precipitation diagrams for aluminium alloys AA7150 and AA7020. J Alloys Compd 584:581-589. https://doi.org/10.1016/j.jallcom. 2013.09.014

[22] Milkereit B, Österreich M, Schuster P, Kirov G, Mukeli E, Kessler O (2018) Dissolution and precipitation behavior for hot forming of 7021 and 7075 aluminum alloys. Metals 8(7 (531)). https://doi.org/10.3390/met8070531

[23] Zhang Y, Weyland M, Milkereit B, Reich M, Rometsch PA (2016) Precipitation of a new platelet phase during the quenching of an Al-Zn-Mg-Cu alloy. Sci Rep 6:23109. h ttps://doi.org/10.1038/srep23109
[24] Liu S, Li Q, Lin H, Sun L, Long T, Ye L, Deng Y (2017) Effect of quench-induced precipitation on microstructure and mechanical properties of 7085 aluminum alloy. Mater Des 132:119-128. https://doi.org/10.1016/j.matdes.2017.06.054

[25] Liu S, Zhang M, Li Q, Zhu Q, Song H, Wu X, Cao L, Couper MJ (2020) Effect of quenching rate on strengthening behavior of an $\mathrm{Al}-\mathrm{Zn}-\mathrm{Mg}-\mathrm{Cu}$ alloy during natural ageing. Mater Sci Eng A 793:139900. https://doi.org/10.1016/j.mse a.2020.139900

[26] Ostermann F (2014) Anwendungstechnologie Aluminium, 3rd edn. Springer-Verlag, Berlin, Heidelberg, VDI-Buch

[27] Schumacher P (2018) Plastisches verformungsverhalten unterkühlter aluminiumlegierungen im system Al-Mg-Si. $\mathrm{PhD}$ thesis, Universität Rostock

[28] Fang X, Song M, Li K, Du Y, Zhao D, Jiang C, Zhang H (2012) Effects of $\mathrm{Cu}$ and $\mathrm{Al}$ on the crystal structure and composition of $\eta(\mathrm{MgZn} 2)$ phase in over-aged Al-Zn-Mg$\mathrm{Cu}$ alloys. J Mater Sci 47(14):5419-5427. https://doi.org/10. 1007/s10853-012-6428-9

[29] Liang P, Tarfa T, Robinson JA, Wagner S, Ochin P, Harmelin MG, Seifert HJ, Lukas HL, Aldinger F (1998) Experimental investigation and thermodynamic calculation of the Al-MgZn system. Thermochim Acta 314(1-2):87-110

[30] Starink MJ, Milkereit B, Zhang Y, Rometsch PA (2015) Predicting the quench sensitivity of Al-Zn-Mg-Cu alloys: A model for linear cooling and strengthening. Mater Des 88:958-971. https://doi.org/10.1016/j.matdes.2015.09.058

Publisher's Note Springer Nature remains neutral with regard to jurisdictional claims in published maps and institutional affiliations. 